\title{
Films of Post-Consumer Polypropylene Composites for the Support Layer in Synthetic Paper
}

\author{
Cristiano R. de Santi, Ana Carolina Correa, Sati Manrich \\ Departamento de Engenharia de Materiais, 3R-NRR, UFSCar
}

\begin{abstract}
Composite films were studied as possible candidates for the central or support layer of synthetic paper in a multilayer structure. Recycled post-consumer polypropylene films were reinforced with inorganic fillers at various compositions and under several processing conditions, with the aim of optimizing the physical and mechanical properties of rigidity and low density. Three types of $\mathrm{CaCO}_{3}$, with and without surface treatment of the particles, were used, but only the treated ones were suitable for use in paper films. These samples were then used to analyze possible correlations of properties with composition and processing conditions, varying the $\mathrm{CaCO}_{3}$ particle size distribution and the film processing method, from casting extrusion (flat die) to blown-film extrusion (tubular die). An increase in film stiffness was observed as a function of $\mathrm{CaCO}_{3}$ content and a concentration of $30 \% \mathrm{CaCO}_{3}$ was found to be best for the specific application. The flat films were stiffer than the tubular ones. The densities of all the composite films were considered high, compared to a pulp-based paper and a commercial synthetic paper. No significant effect on the physical-mechanical properties analyzed was observed when the $\mathrm{CaCO}_{3}$ particle size distribution was varied. Microcavities were found to form at the surface of flat films submitted to a bi-orientation process performed at laboratory scale; no other sample showed this surface morphology.
\end{abstract}

Keywords: Polypropylene, synthetic paper, post-consumer waste, composite, oriented film.

\section{Introduction}

World levels of production and consumption of paper have been growing for decades. The average growth-rate of world demand was $3.6 \%$ a year in the 1980 s and $3.3 \%$ a year in the first half of the 1990s, and similar rates are estimated for the ten years from 1995 until 2005 ${ }^{[1]}$. In Brazil in 2004, 9.4 million tons of cellulose and 8.2 million tons of paper were produced, representing 3.6\% more than in 2003 and verifying the above world projection ${ }^{[2,3]}$. Paper production in 2005 was estimated to rise by $3.5 \% \%^{[3]}$. To satisfy this demand, the Brazilian government has announced a total investment of US\$ 14.4 billion in the sector ${ }^{[4,5]}$. Just for 2004, it was predicted that the country would need to plant 135 million $\mathrm{m}^{3}$ of forest, while the available timber for paper in that year was forecast as 125 million $\mathrm{m}^{3}$.

Synthetic paper is fabricated from thermoplastic polymers, virgin or recycled, formed into a film that accepts writing or printing, like cellulose paper. In contrast to the latter, whose raw material is extracted from natural resources and whose production and treatment have a great impact on the environment, synthetic paper is produced by an almost totally clean method and thus helps to conserve the environment and natural resources, especially if discarded plastic can be used as raw material in the process ${ }^{[7]}$.

Plastic package recycling has become a cause for concern among societies around the world, faced with a growing volume of such packaging in use and the inevitable environmental consequences of uncontrolled post-consumer disposal ${ }^{[8]}$. The profitability of the market in recycled plastic packaging in Brazil indicates that this sector holds attractive features for commercial initiatives, with direct socioeconomic gains such as a better quality of life for the population, the generation of earnings, economical use of natural resources and reduced environmental problems.

At present, $17 \%$ of all rigid and film plastic consumed in Brazil is recycled back into the productive chain as raw material. Of this recycled plastic, $60 \%$ comes from industrial residues and $40 \%$ is post-consumer ${ }^{[9]}$. Recycling is a potential source of low-cost products that reduces the consumption of virgin raw material and the environmental impact of waste. Therefore, it is worth investing a lot of effort in decreasing the wastage of the remaining $83 \%$ that is thrown away, in most cases dropped in open spaces.

Bearing in mind the twin environmental problems of the shortfall in natural resources for paper-making and the improper disposal of a growing mass of waste plastic, a group at the 3R-nrr (3R-Núcleo de Reciclagem de Resíduos -3R-Residue Recycling Center) has developed researches on recycling of polymer residues into composite films for use in the fabrication of synthetic paper. Currently, the group is studying possible multilayer structures and the focus of this article is the production of the central support layer, consisting of a polypropylene (PP) film, derived from post-

Corresponding author: Sati Manrich, Departamento de Engenharia de Materiais/3R-NRR, UFSCar, CEP: 13565-905, São Carlos, SP, Brasil. E-mail: sati@power.ufscar.br 
consumer PP (PPr) residues and reinforced with polyester fibers (made from recycled PET) and inorganic fillers. The main objective of the present study was to optimize the physical properties of high rigidity and low density, so desirable in a support layer, specifically in PPr filled with $\mathrm{CaCO}_{3}$ powder. These properties are compared with those observed in natural and commercial synthetic paper.

\section{Experimental}

Only municipal solid waste was used in the polymer matrix of the films, which consisted basically of recycled postconsumer PP from selected rigid food packaging and used mineral-water bottles. To this matrix were added a filler, powdered natural calcium carbonate $\left(\mathrm{CaCO}_{3}\right)$, and an antistatic agent.

To analyze the influence of filler granulometry on the physical properties under study, three types of calcium carbonate with differing particle-size distributions were tested: Supermicro K, Supermicro K RVA and Carbital 110S. The last two of these were surface-treated with stearic acid $\mathrm{CH}_{3}\left(\mathrm{CH}_{2}\right)_{16} \mathrm{COOH}$ - and calcium stearate, giving a total fatty acid content of $1 \%{ }^{[10,11]}$ according to data from the supplier, whereas Supermicro K is untreated. Dimodan (Danisco Ingredients Inc.) was employed as internal antistatic agent. This monoglyceride compound is recommended for polyolefin injection and extrusion processes.

Waste PP was collected from the Selective Waste Center at the São Carlos Federal University (UFSCar), which is a voluntary disposal point for recyclable trash, and separated into two lots: mineral water bottles (bulk-size and individual) and food containers (margarine boxes, yoghurt pots, dried milk jars, etc.). The material was then cleaned by conventional methods to remove labels and seals, ground into flakes, washed, dried and then granulated in a single-screw extruder. The melt flow index of the two lots of recycled PP (PPr) was measured with a Davenport MFI-10 equipment, in conformity with ASTM D-1238 (2.16 kg; $\left.230^{\circ} \mathrm{C}\right)$.

Before the mixing stage, both the filler and the $\mathrm{PP}$ granules were dried for $24 \mathrm{~h}$ in an oven at $50{ }^{\circ} \mathrm{C}$. The $\mathrm{PPr} / \mathrm{CaCO}_{3}$ composites, in the proportions 90:10, 80:20, 70:30 and 60:40 by weight, were mixed in a Drais high-intensity mixer, resulting in a paste which was further chopped in a blade mill and then granulated by extruding from a Gerst $25 \times 24 \mathrm{D}$ singlescrew extruder (temperature program $170 / 180 / 200{ }^{\circ} \mathrm{C}$ ) and cutting the emerging strands.

The composite granules were again dried at $50{ }^{\circ} \mathrm{C}$ for $24 \mathrm{~h}$, before processing into film. The flat dye-cast films were extruded from the same Gerst extruder, set to a speed of rotation of 25rpm and a temperature program of 190/200/ $210^{\circ} \mathrm{C}$. A standard film of $\mathrm{PPr}$ without filler was processed in the same way, for comparison. The processability of the composites was assessed in terms of the regularity and stability of the process and the quality of the films evaluated by their homogeneity, dispersion and distribution of the filler particles at the surface.
In those films that met the requirements for processability and quality, further quantitative and qualitative characteristics were studied: density (ASTM D792-86), which was compared with the theoretical value calculated from the mass fraction and density of each component in the film (using a weightedaverage formula); surface morphology observed by scanning electron microscopy (SEM); Young's elastic modulus (ASTM D882-90); elongation at break and tensile strength (ASTM D882-90). Young's modulus was only measured in the longitudinal direction, because the film samples were not wide enough to make transverse measurements in conformity with the standard.

To study the influence of the processing type, tubular films were made with the same type of $\mathrm{CaCO}_{3}$ as in the flat films (Supermicro K RVA), in the same mass fraction, and antistatic (Dimodan) was added to $0.5 \%$. These ingredients were mixed to an even composition in an Imacom twin-screw extruder (DRC-25), running at $160 \mathrm{rpm}$, with the temperature program $95 / 150 / 160 / 160 / 185 / 190 / 190 / 205 / 205 / 210 / 215{ }^{\circ} \mathrm{C}$. The resulting composite was blow-extruded into tubular films in a Ciola IF-40 extruder, $\mathrm{L} / \mathrm{D}=25$, operated at $48 \mathrm{rpm}$, with the program $190 / 200 / 210 / 210 / 220{ }^{\circ} \mathrm{C}$ and a pulling rate of $9.5 \mathrm{~m} / \mathrm{min}$. The quality of these films was evaluated by SEM, as in the case of the flat films.

The effects of varying the calcium carbonate particle size distribution and the degree of stretching of the film were investigated in films with the composition (70:30) found to give the best results in both flat and tubular films. Identical conditions were used to mix the composite in the Imacon extruder and to extrude the films in the Ciola IF-40, in all these tests. In the $\mathrm{CaCO}_{3}$ granulometric test, Supermicro K RVA was replaced by Carbital 110S, which has a narrower distribution of particle sizes. In addition to the pulling rate used in other tests $(9.5 \mathrm{~m} / \mathrm{min})$, films were stretched at 14.6 and $22.0 \mathrm{~m} / \mathrm{min}$, the latter being the highest speed that afforded process stability with these composites.

A bench-scale test of film biorientation was carried out on flat films of composition 70:30 and 60:40. A device capable of stretching films uniaxially was installed in a muffle furnace and the films were stretched up to 4 times in the transverse direction, at $135^{\circ} \mathrm{C}$. The resulting biaxially-stretched films were examined by SEM, to analyze the microstructural effects of biorientation.

\section{Results and Discussion}

\section{General characteristics}

By homogenizing the plastic flakes in the initial extrusion process, the variability of the MFI arising from the diversity of collected material was minimized within each of the two kinds of PPr collected. Rather low flow indices were predicted for PPr, since most discarded packaging is manufactured in processes in which virgin PP resin of low MFI has to be used, such as thermoforming and blow molding. The mean experimental values were $2.4 \mathrm{~g} / 10 \mathrm{~min}$ for water-bottle $\mathrm{PPr}$ and $3.9 \mathrm{~g} / 10 \mathrm{~min}$ for PPr from food containers. 
Composites filled with $\mathrm{CaCO}_{3}$ that had not been surfacetreated were of low quality. Even with $10 \%$ of the filler, aggregated particles were seen in these composites and, when the load was increased to $30 \%$ and $40 \%$, the films could not be pulled, as the melted mixture continually tore at the die exit. In contrast, when treated $\mathrm{CaCO}_{3}$ was used, up to $30 \%$ of the filler gave composites with excellent processability and films of fine appearance. When the content was raised to $40 \%$ by weight, small clumps of filler particles appeared, but these were not serious enough to affect the film quality.

When tubular film was produced at the highest pulling speed $(22 \mathrm{~m} / \mathrm{min})$ from mixtures containing Supermicro K RVA in any proportion, it was impossible to stabilize the process as the emerging bubble would tear. However, when Carbital 110S, which has smaller particles and a narrower distribution of sizes, was used in the composite, the bubble was stable and no problems were encountered at any of the three pulling speeds. The larger total surface area of finer smaller $\mathrm{CaCO}_{3}$ particles allows greater interaction between the polymer and filler, raising the viscosity of the melt ${ }^{[12]}$ and improving the stability of the process at high pulling speeds, as observed here.

\section{Analysis of surface micrographs}

The surfaces of the composite films were examined by SEM, in order to observe the porosity and presence of microvoids in the film, as well as the degree of dispersion of the mineral filler, and thus gather important structural information that could be correlated with the mechanical properties and densities of the films.

The blown (tubular) films exhibited a surface structure similar to that of the flat films, where a good distribution, dispersion and compatibility of the filler were observed (see Figure 1). However, the biorientation of the blown films apparently did not give rise to any microvoids, at least at the surface. Moreover, reduction of the particle size of the filler did not lead to any appreciable change in the film microstructure.

As described above, flat monooriented films with $30 \%$ and $40 \% \mathrm{CaCO}_{3}$ were subjected to a second, extensive orientation in the transverse direction by a purpose-built device to stretch films in a heated oven. In this case, microcavities were found to have formed in the surface of the film. These varied in size, the largest arising from the larger mineral particles, as can be seen in detail in Figure 2. Owing to the small mass and size of the bioriented flat film samples, other tests of the effects of these cavities, such as measuring the film density or mechanical properties, could not be carried out.

There is general agreement in most of the consulted patents and articles on synthetic paper ${ }^{[17-19]}$ that the formation of microcavities during biorientation of the films is an important stage in the manufacturing process. Microcavities are small cavities that appear at the interface of two distinct phases, in this case polymer matrix and filler, while microvoids is the general term referring to any microscopic cavities.

The measured densities of films of various compositions

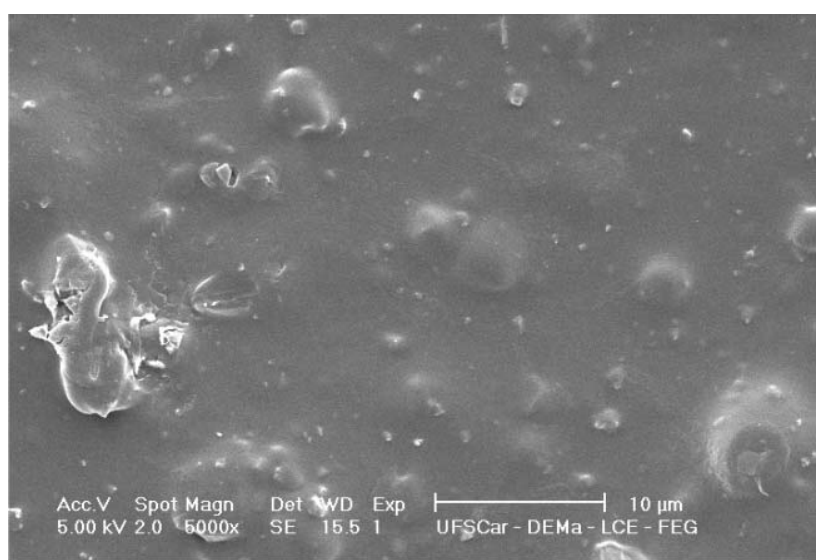

Figure 1. Film surface morphology - Tubular film of $\mathrm{PP} / 40 \mathrm{wt} \% \mathrm{CaCO}_{3}$ Supermicro K RVA (5000x)

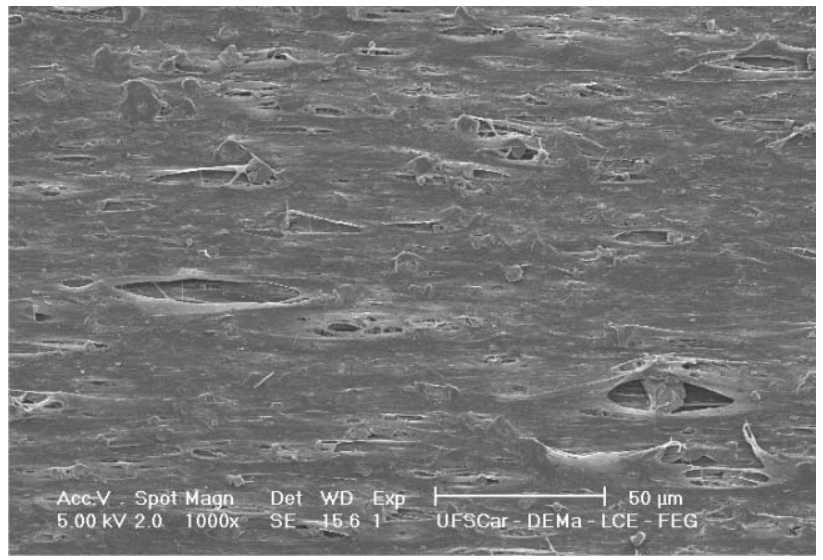

Figure 2. Film surface morphology - Extensively bioriented flat film of $\mathrm{PP} / 40 \mathrm{wt} \% \mathrm{CaCO}_{3}$ Supermicro K RVA (1000x)

and processed in different ways are displayed in Table 1, together with those of samples of commercial cellulose and synthetic paper. The density is seen to rise with increasing $\mathrm{CaCO}_{3}$ content, as would be expected from the known density of this mineral, around $2.6 \mathrm{~g} \mathrm{~cm}^{-3}$. However, it is apparent that, as the fraction of filler increases, the real density falls farther and farther below the theoretical value, going from about $10 \%$ down (at 10\% filler) to around $18-19 \%$ less than expected (at 30\% filler), where the deviation levels to a plateau. This implies a density-reducing effect caused by the incorporation of $\mathrm{CaCO}_{3}$, even in the absence of any biorientation process, which would have induced the formation of microcavities, leading to a fall in density. Moreover, the results in the table show that increasing the film-pulling speed did not have the effect of reducing the density, which might have occurred if the higher shear-rates induced by faster orientation had created microcavities in the film. In fact, as already observed, no microvoids at all were visible in these monooriented and partially bi-oriented (tubular) samples, at least not on the surface. It may also be noted that changing the size of the $\mathrm{CaCO}_{3}$ particles made no difference to their density-reducing effect.

The Young's moduli (E) of the films are listed in Table 2. These refer only to the modulus measured along the longitudinal axis, as explained in the Experimental section. 
Table 1. Film density results

\begin{tabular}{|c|c|c|c|c|}
\hline Type of film & Content / Type of $\mathrm{CaCO}_{3}$ & $\begin{array}{c}\text { Measured Density } \\
\left(\mathrm{g} / \mathrm{cm}^{3}\right)\end{array}$ & $\begin{array}{l}\text { Theoretical Density } \\
\qquad\left(\mathrm{g} / \mathrm{cm}^{3}\right)\end{array}$ & $\%$ Diference \\
\hline Flat & 0 & $0.904 \pm 0.005$ & 0.905 & 0 \\
\hline Flat & 10\% / Supermicro K RVA & $0.954 \pm 0.032$ & $1.052 \pm 0.005$ & -9.3 \\
\hline Flat & $20 \%$ / Supermicro K RVA & $1.051 \pm 0.022$ & $1.219 \pm 0.012$ & -13.8 \\
\hline Flat & $30 \%$ / Supermicro K RVA & $1.114 \pm 0.040$ & $1.356 \pm 0.005$ & -17.8 \\
\hline Flat & $40 \%$ / Supermicro K RVA & $1.216 \pm 0.025$ & $1.488 \pm 0.007$ & -18.3 \\
\hline Commercial synthetic paper & n.a. & $0.913 \pm 0.030$ & - & - \\
\hline Cellulose paper & n.a. & $0.725 \pm 0.015$ & - & - \\
\hline Tubular & 0 & $0.901 \pm 0.005$ & 0.905 & -0.3 \\
\hline Tubular & $10 \%$ / Supermicro K RVA & $0.952 \pm 0.025$ & $1.061 \pm 0.017$ & -10.3 \\
\hline Tubular & $20 \%$ / Supermicro K RVA & $1.095 \pm 0.051$ & $1.229 \pm 0.012$ & -10.9 \\
\hline Tubular & $30 \%$ / Supermicro K RVA & $1.109 \pm 0.024$ & $1.380 \pm 0.022$ & -19.6 \\
\hline Tubular & $40 \%$ / Supermicro K RVA & $1.225 \pm 0.019$ & $1.510 \pm 0.005$ & -18.9 \\
\hline Tubular $(*)$ & $30 \%$ / Supermicro K RVA & $1.109 \pm 0.024$ & $1.380 \pm 0.022$ & -19.6 \\
\hline Tubular $(* *)$ & $30 \%$ / Supermicro K RVA & $1.067 \pm 0.018$ & $1.380 \pm 0.022$ & -22.7 \\
\hline Tubular $(*)$ & $30 \%$ / Carbital C110S & $1.110 \pm 0.038$ & $1.358 \pm 0.022$ & -18.3 \\
\hline Tubular $(* *)$ & $30 \%$ / Carbital C110S & $1.177 \pm 0.021$ & $1.358 \pm 0.022$ & -13.3 \\
\hline Tubular $(* * *)$ & $30 \%$ / Carbital C110S & $1.141 \pm 0.024$ & $1.358 \pm 0.022$ & -16.0 \\
\hline
\end{tabular}

(*) Condition 1: film pulling rate $9.5 \mathrm{~m} / \mathrm{min}$

(**) Condition 2: film pulling rate $14.6 \mathrm{~m} / \mathrm{min}$

(***) Condition 3: film pulling rate $22.0 \mathrm{~m} / \mathrm{min}$

The results showed that the addition of $\mathrm{CaCO}_{3}$ had stiffened the films, as the value of $\mathrm{E}$ increased with the fraction of filler. This verified quantitatively what had first been proved qualitatively, by the appearance and feel of the film. It has been reported by a number of authors ${ }^{[12-15]}$ that raising the $\mathrm{CaCO}_{3}$ content led to considerable increases in the elastic modulus of injection-molded test-pieces; the present results confirm this behavior both in flat and tubular films, with the increment in $\mathrm{E}$ reaching $40 \%$ at about $40 \% \mathrm{CaCO}_{3}$.

Although the composite blown films showed the same increment in $\mathrm{E}$ as the flat films, as the filler content rose, the actual values of $E$ resulting from this process of biaxial orientation were lower than those of the uniaxial flat films.

Neither variation of the film-pulling speed nor changing the type of $\mathrm{CaCO}_{3}$, to alter the mean size and size distribution of the particles, had a significant effect on the value of Young's modulus. There was, nevertheless, a slight tendency for higher pulling speeds to lead to lower values of $\mathrm{E}$, particularly when films pulled at $14.6 \mathrm{~m} / \mathrm{min}$ and $9.5 \mathrm{~m} / \mathrm{min}$ were compared.

The results of testing the films under tension are shown in Table 3. In general, the flat films, in which the orientation was predominantly uniaxial, had significantly greater tensile strength along the longitudinal axis (machine direction) than at right-angles to it (transversal direction). This may be explained by the fact that many of the polymer molecules are oriented along this axis during processing. The sample of cellulose paper behaved similarly with respect to its tensile strength.

The commercial synthetic paper sample was an exception. Probably, extensive biorientation during its production ${ }^{[17-19]}$, coupled with a multilayer structure including a surface coating, resulted in a considerably greater longitudinal tensile strength, but significantly lower elongation at break, than in the other polymer films, including the cellulose paper.

As foreseen in above-mentioned articles ${ }^{[13-15]}$ and elsewhere in the literature, the value of $\sigma_{\max }$ fell as the calcium carbonate content increased, especially at concentrations above $20 \%$. However, in both flat and tubular films, there was a small increase in strength when $10 \%$ filler was added to the film without filler. This trend can only be verified by conducting tests on films whose composition varies within this range.

With regard to the elongation at break $\left(\varepsilon_{\mathrm{r}}\right)$, the large standard deviation of the tested samples prevents a proper analysis of any kind of correlation, but it can be seen that all the longitudinal values were higher than those measured across the film. This wide variability of $\varepsilon_{\mathrm{r}}$ has been noted in thermoplastic-based films and injection-molded plastics that are subjected to extensive molecular orientation by pulling at ambient temperature, such as HDPE, PP and PET ${ }^{[20]}$. The behavior of cellulose paper was the opposite of that of the polymer films, the transverse elongation being greater than the longitudinal. This was initially attributed to the very 
Table 2. Film elastic modulus

\begin{tabular}{|c|c|c|}
\hline Type of film & Content / Type of $\mathrm{CaCO}_{3}$ & $\begin{array}{c}\text { Elastic modulus } \\
\quad(\mathrm{MPa})\end{array}$ \\
\hline Flat & 0 & $1,587 \pm 26$ \\
\hline Flat & $10 \%$ / Supermicro K RVA & $1,769 \pm 115$ \\
\hline Flat & $20 \%$ / Supermicro K RVA & $1,881 \pm 141$ \\
\hline Flat & $30 \%$ / Supermicro K RVA & $1,896 \pm 70$ \\
\hline Flat & $40 \%$ / Supermicro K RVA & $2,134 \pm 424$ \\
\hline $\begin{array}{l}\text { Commercial } \\
\text { synthetic paper }\end{array}$ & n.a. & $983 \pm 20$ \\
\hline Cellulose paper & n.a. & $7,108 \pm 29$ \\
\hline Tubular & 0 & $591 \pm 52$ \\
\hline Tubular & $10 \%$ / Supermicro K RVA & $667 \pm 47$ \\
\hline Tubular & $20 \%$ / Supermicro K RVA & $761 \pm 75$ \\
\hline Tubular & $30 \%$ / Supermicro K RVA & $861 \pm 23$ \\
\hline Tubular & $40 \%$ / Supermicro K RVA & $956 \pm 67$ \\
\hline Tubular $(*)$ & $30 \%$ / Supermicro K RVA & $861 \pm 23$ \\
\hline Tubular $(* *)$ & $30 \%$ / Supermicro K RVA & $758 \pm 59$ \\
\hline Tubular $(*)$ & $30 \%$ / Carbital C110S & $863 \pm 23$ \\
\hline Tubular $(* *)$ & $30 \%$ / Carbital C110S & $760 \pm 40$ \\
\hline Tubular $(* * *)$ & $30 \%$ / Carbital C110S & $827 \pm 31$ \\
\hline
\end{tabular}

different manufacturing processes and microstructures of cellulose paper compared to composite thermoplastic films. However, it is more reasonable to assume that the long axis of the sheet of paper was in fact transverse to the orientation of the paper making machine.

The tensile strength of the blown tubular films was similar to that of the flat films in the longitudinal direction, while the difference between values measured transversely and longitudinally was slightly lower for tubular film samples. This may be attributed to the fact that some molecular orientation also occurs at right-angles to the direction in which the film is pulled, in the tubular process. This biorientation had a more noticeable effect on the elongation at break of these blown films, which was found to be much higher than in the flat films. However, a trend contrary to that of the flat films was observed with respect to the fraction of filler; the $\stackrel{\circ}{\mathrm{r}}_{\mathrm{r}}$ values of tubular films decreased as $\mathrm{CaCO}_{3}$ content rose. This effect has been noted elsewhere ${ }^{[13-15]}$.

Analyzing the results of varying the composition and processing conditions, it is found that films containing the $\mathrm{CaCO}_{3}$ with the smallest mean particle size (C110S) exhibited slightly superior tensile strength, in both the longitudinal and transverse directions, while the elongation at break was unaffected by this factor. Finally, no correlation was seen between the film-pulling speed and either of these properties, within the range tested.

$(*),(* *),(* * *)$ The same film pulling conditions described in Table 1

Table 3. Maximum tensile strength $\left(\sigma_{\text {max }}\right)$ and elongation at break $\left(\varepsilon_{\mathrm{r}}\right)$ of film samples

\begin{tabular}{|c|c|c|c|c|c|}
\hline \multirow[b]{2}{*}{ Type of film } & \multirow[b]{2}{*}{ Content / Type of $\mathrm{CaCO}_{3}$} & \multicolumn{2}{|c|}{ Longitudinal (MD) } & \multicolumn{2}{|c|}{ Transversal (TD) } \\
\hline & & $\begin{array}{c}\sigma_{\max } \\
(\mathbf{M P a})\end{array}$ & $\begin{array}{c}\varepsilon_{\mathrm{r}} \\
(\%)\end{array}$ & $\underbrace{\sigma_{\max }}_{\text {(MPa) }}$ & $\begin{array}{c}\varepsilon_{\mathrm{r}} \\
(\%)\end{array}$ \\
\hline Flat & 0 & $43.5 \pm 3.8$ & $512 \pm 80$ & $30.4 \pm 1.6$ & $95 \pm 58$ \\
\hline Flat & $10 \%$ / Supermicro K RVA & $47.7 \pm 3.9$ & $602 \pm 23$ & $17.0 \pm 2.7$ & $260 \pm 160$ \\
\hline Flat & $20 \%$ / Supermicro K RVA & $44.8 \pm 3.3$ & $461 \pm 130$ & $15.1 \pm 2.9$ & $110 \pm 81$ \\
\hline Flat & $30 \%$ / Supermicro K RVA & $37.5 \pm 3.3$ & $610 \pm 67$ & $17.7 \pm 0.5$ & $130 \pm 103$ \\
\hline Flat & $40 \%$ / Supermicro K RVA & $32.9 \pm 1.5$ & $317 \pm 60$ & $13.5 \pm 1.2$ & $73 \pm 89$ \\
\hline Commercial synthetic paper & n.a. & $103 \pm 6$ & $22.2 \pm 3.3$ & $36.2 \pm 2.8$ & $114 \pm 16$ \\
\hline Cellulose paper & n.a. & $60.5 \pm 2.8$ & $4.2 \pm 0.7$ & $30.3 \pm 1.8$ & $8.3 \pm 1.3$ \\
\hline Tubular & 0 & $40.4 \pm 3.7$ & $747 \pm 38$ & $24.7 \pm 0.9$ & $588 \pm 252$ \\
\hline Tubular & $10 \%$ / Supermicro K RVA & $42.0 \pm 5.4$ & $809 \pm 70$ & $24.9 \pm 2.5$ & $840 \pm 43$ \\
\hline Tubular & $20 \%$ / Supermicro K RVA & $36.6 \pm 4.8$ & $656 \pm 70$ & $23.3 \pm 2.5$ & $670 \pm 162$ \\
\hline Tubular & $30 \%$ / Supermicro K RVA & $32.3 \pm 3.2$ & $677 \pm 78$ & $16.9 \pm 2.1$ & $572 \pm 126$ \\
\hline Tubular & $40 \%$ / Supermicro K RVA & $27.2 \pm 2.6$ & $599 \pm 27$ & $15.0 \pm 0.7$ & $500 \pm 51$ \\
\hline Tubular (*) & $30 \%$ / Supermicro K RVA & $32.3 \pm 3.2$ & $677 \pm 78$ & $16.9 \pm 2.1$ & $572 \pm 126$ \\
\hline Tubular (**) & $30 \%$ / Supermicro K RVA & $29.4 \pm 2.9$ & $562 \pm 57$ & $18.3 \pm 1.3$ & $616 \pm 79$ \\
\hline Tubular (*) & $30 \%$ / Carbital C110S & $34.4 \pm 5.5$ & $642 \pm 73$ & $21.0 \pm 2.5$ & $688 \pm 61$ \\
\hline Tubular $(* *)$ & $30 \%$ / Carbital C110S & $35.1 \pm 3.8$ & $620 \pm 59$ & $20.8 \pm 1.9$ & $630 \pm 70$ \\
\hline Tubular (***) & $30 \%$ / Carbital C110S & $37.2 \pm 3.5$ & $648 \pm 33$ & $18.5 \pm 0.7$ & $639 \pm 28$ \\
\hline
\end{tabular}

(*) Condition 1: film pulling rate $9.5 \mathrm{~m} / \mathrm{min}$

(**) Condition 2: film pulling rate $14.6 \mathrm{~m} / \mathrm{min}$

(***) Condition 3: film pulling rate $22.0 \mathrm{~m} / \mathrm{min}$ 


\section{Conclusions}

The recycled polymer composites evaluated in this study, with a view to using them in the support layer of multilayer synthetic paper, were shown to be viable in terms of the processability of the polymer mixture and the extrusion of films. Important factors that contributed to the practicality of this investigation were the ready availability of the recycled post-consumer source material, the relative ease with which polypropylene is separated from the rest of the waste and the fact that its average melt flow index is suitable for direct application in film extrusion.

The composites produced by the two different mixing processes, using the high-intensity rotary mixer and the twinscrew extruder, did not exhibit significant differences in processability or in the properties of the films prepared from those composites, such as dispersion of mineral filler, mechanical properties and final appearance.

The calcium carbonate without any surface treatment proved completely inadequate as a filler for recycled PP films, demonstrating the importance of promoting some kind of filler-polymer interaction to ensure a good dispersion of the particles and hence the reinforcement of the film.

In general, the films were found to become stiffer as the $\mathrm{CaCO}_{3}$ content was raised, the optimal concentration being $30 \%$ by weight, because the appearance of the films was not spoiled by the presence of aggregated particles, as happened at higher contents. Films extruded through a flat die were stiffer than the blown films, which was explained by the greater degree of molecular orientation in the direction of flow that occurs in monooriented films.

The variation in granulometric distribution among the varieties of $\mathrm{CaCO}_{3}$ tested did not affect the mechanical properties evaluated, in particular Young's modulus, except that there was a modest rise of $10 \%$ to $15 \%$ in tensile strength when the mean particle size was reduced by $35 \%$.

The densities of the PP films were higher than that of cellulose paper and were found to rise as the filler content increased, but at an appreciably lower rate than would be predicted, assuming a simple additive effect. This behavior can probably be attributed to the formation of microvoids, perhaps microcavities, in proportion to the number of filler particles, which would reduce the apparent density. These are presumed to exist in the bulk of the composite, though they generally were not observed at the surface.

Surface microcavities were seen, however, in SEM micrographs of small samples of film subjected to extensive biorientation. Owing to their small dimensions, the densities of these samples could not be determined, making it impossible to study the effect of the cavities on film density. In future experiments, biorientation on a larger scale is planned, to clarify this question.

\section{Acknowledgements}

The authors thank to FAPESP (Proc. 03/06113-0) for financial support and to CNPq and CAPES for students' scholarships.

\section{References}

1. "O Setor de Papel e Celulose no Brasil e no Mundo", BNDES, (1996).

2. "Produção e Exportação em Alta: Resultados de 2004 Refletem Esforço do Setor" - O Papel, ABTCP, LXV, 12, p. 46, (2004).

3. "Desempenho de Setor em 2004 e Perspectivas Para 2005" Bracelpa News, Brazilian Association of Cellulose and Paper, XI, 525, (2005).

4. "Oportunidade para o Crescimento" - Bracelpa News, Brazilian Association of Cellulose and Paper, XI, 520, (2004).

5. "Uma Advertência Muito Séria" - Celulose \& Papel, Bracelpa, 20, 75, p.3, (2004).

6. "A Madeira Vai Virar Ouro" - O Papel, ABTCP, LXV, 5, p.98, (2004).

7. Almeida, M.C.; Manrich, S. - Polímeros: Ciência e Tecnologia, vol.12, 1, p. 20-27, (2002).

8. Forlin, F.J.; Faria, J.A.F. - Polímeros: Ciência e Tecnologia, vol.12, 1, p. 1-10, (2002).

9. Technical Catalogs CEMPRE, http://www.cempre.org.br

10. Technical Bulletin Supermicro KRVA, Imerys do Brasil Mineração Ltda, Rev.03, April 2003.

11. Data Sheet DAT206CC Carbital 110S, Imerys Minerals Ltd, Second Edition, (2001).

12. Zuiderduin, W.C.J.; Westzaan, C.; Huétink, J.; Gaymans, R.J. Polymer, 44, p. 261-275, (2003).

13. Liang, J. Z.; Tang, C. Y.; Li, R. K. R.; Wong T.T. - Metals and Materials, v. 4, p. 616-619, (1998).

14. Thio, Y.S.; Argon, A.S.; Cohen, R.E.; Weinberg, M. - Polymer, 43, p. 3661-3674, (2002).

15. Silva, A.L.N.; Rocha, M.C.G.; Moraes, M.A.R.; Valente, C.A.R.; Coutinho, F.M.B. - Polymer Testing, 21, p. 57-60, (2002).

16. Miller, M.L. - "Encyclopedia of Polymer Science and Technology: Plastics, Resins, Rubbers, Fibers", vol.1, Interscience Publishers, New York, (1964).

17. Ohno, A.; Goseishi, O.Y. - "Synthetic Paper with Multi-Layer Structure and Excellent Printing Property", Patent EP 685,331 A1, (1995).

18. Mannar, S.M. - "Synthetic Paper and a Process for Making It', Patente EP 605,938 A1 940,713, (1993).

19. Squier, J.A.H.; Osgood JR, R.W.; Perez, K.B.; Williams, D.R. "Thermoplastic Film Label Composite with a Printable, Untreated, Cavitated Surface”, Patent US 6,787,217, (2004).

20. Ravazi, R.F. - "Estudo de Aditivação, Composição e Processamento de Resíduos Plásticos Rígidos Pós-Consumo para a Fabricação de Papel Sintético", Master Dissertation, PPG-CEM/UFSCar, Brazil, (2002).

Enviado: $21 / 10 / 05$

Reenviado: 14/03/06

Aprovado:28/03/06 